\title{
Optically stimulated luminescence (OSL) dating of quartzite cobbles from the Tapada do Montinho archaeological site (east-central Portugal)
}

\author{
REZA SOHBATI, ANDREW S. MURRAY, JAN-PIETER BUYLAERT, NELSON A. C. ALMEIDA AND PEDRO P. CUNHA
}

\section{BOREAS}

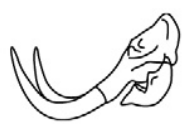

Sohbati, R., Murray, A. S., Buylaert, J.-P., Almeida N. A. C. \& Cunha, P. P. 2012 (July): Optically stimulated luminescence (OSL) dating of quartzite cobbles from the Tapada do Montinho archaeological site (east-central Portugal). Boreas, Vol. 41, pp. 452-462. 10.1111/j.1502-3885.2012.00249.x. ISSN 0300-9483.

The burial age of an alluvially deposited cobble pavement at the Tapada do Montinho archaeological site (east-central Portugal) is investigated using optically stimulated luminescence (OSL) dating. Measurements on the cobbles (quartzite clasts) were carried out on intact slices and large aliquots $(\sim 8 \mathrm{~mm})$ of quartz grains $(63-$ $300 \mu \mathrm{m})$, both recovered from the outer $1.5-\mathrm{mm}$ surface of the cobbles. The recycling ratio, recuperation and dose-recovery tests show that the single-aliquot regenerative-dose (SAR) protocol is applicable to both rock slices and quartz grains; both have similar luminescence characteristics. The variation in the natural OSL signal with depth below the cobble surface using intact slices from two different cobbles shows that both were bleached to a depth of at least $\sim 2 \mathrm{~mm}$ before deposition. A model of the variation of dose with depth fitted to data from one of the cobbles gives a burial age of $\sim 19 \mathrm{ka}$ and also predicts the dose-depth variation at the time of deposition. Ages based on rock slices suggest that one cobble surface, and the inner parts of two other cobbles experienced a resetting event at $\sim 45 \mathrm{ka}$, consistent with the age control. However, the surfaces of the other cobbles all record light-exposure events in the range 26 to $14 \mathrm{ka}$, suggesting that some of the cobbles were exposed to daylight perhaps more than once in this period. Given the shallow burial depth and unexpectedly young ages of the surrounding and overlying finer-grained sediment, it is suggested that phases of light exposure following surficial erosion are probably responsible for this underestimate. Nevertheless, it is remarkable that we can identify and quantify four events (two light exposures of different durations and two sequential burial periods) in the dose record contained within a single clast, and this suggests that the luminescence dating of rock surfaces may prove, in the future, to be at least as important as sand/silt sediment dating.

Reza Sohbati (e-mail: resih@risoe.dtu.dk) and Andrew S. Murray, Nordic Laboratory for Luminescence Dating, Department of Geoscience, Aarhus University, Risø DTU, DK-4000 Roskilde, Denmark; Jan-Pieter Buylaert, Nordic Laboratory for Luminescence Dating, Department of Geoscience, Aarhus University, Riso DTU, DK-4000 Roskilde, Denmark and DTU Nutech, Technical University of Denmark, DK-4000, Roskilde, Denmark; Nelson A.C. Almeida, IGESPAR -I.P., Extensão do Crato, rua 5 de Outubro, 33, 7430-137 Crato, Portugal; Pedro P. Cunha, Department of Earth Sciences, IMAR-Marine and Environmental Research Centre, University of Coimbra, Portugal; received 2nd December 2011, accepted 5th January 2012.
In the most upstream sector of the Lower Tejo River Basin (east-central Portugal), the Tejo River crosses two quartzite ridges that separate the depressions of Ródão (upstream) and Arneiro (downstream). Palaeolithic artefacts have been found at various locations in the region, including at two recently investigated archaeological sites, Castelejo and Tapada do Montinho (TPM) in the Arneiro depression (Fig. 1). These findings have provided new insights into the human occupation in this area between about 60 and $10 \mathrm{ka}$ (Cunha et al. in press). During an early investigation at the Castelejo site, a $\sim 10$-cm-thick gravel/cobble layer, mainly made up of quartzite cobbles $(\sim 10 \mathrm{~cm}$ in diameter) was identified. It contained middle Palaeolithic artefacts (Mousterian industry) and locally burned clasts (Cunha et al. in press). The constraining sediment layers underneath and on top of this naturally deposited cobble pavement were luminescence-dated to $\sim 100 \mathrm{ka}$ (Cunha et al. 2008) and $\sim 30 \mathrm{ka}$ (Cunha et al. in press), respectively. Later, during excavations at TPM $(\sim 1 \mathrm{~km}$ to the south of Castelejo), a similar cobble pavement with Palaeolithic artefacts was found at a shallower depth.

It would be very desirable to date this and other cobble pavements directly, but unfortunately no routinely applicable method is available. Liritzis (2011) reviews research into the application of luminescence methods to rock surfaces, most of which is related to thermoluminescence (TL) from carbonate clasts. More recently, Sohbati et al. (2011) investigated the optically stimulated luminescence (OSL) properties and natural bleaching of granitic cobbles, and Simms et al. (2011) used OSL to determine the time of burial of a cobble beach deposit in Antarctica.

There are many potential applications of rock surface dating in geology and archaeology. In geology, these include ice-scoured bedrock, ice-transported rocks (erratics), and cobble fans from extreme fluvial events. There is also a wide range of potential applications in archaeology, such as chambered burial mounds, megaliths, field walls and cairns. Knowledge of the time scales involved in these natural and anthro- 
Fig. 1. Location of the Castelejo and Tapada do Montinho Palaeolithic sites in the Arneiro depression (modified from Cunha et al. in press). The inset shows the location of the study area. This figure is available in colour at http://www. boreas.dk.

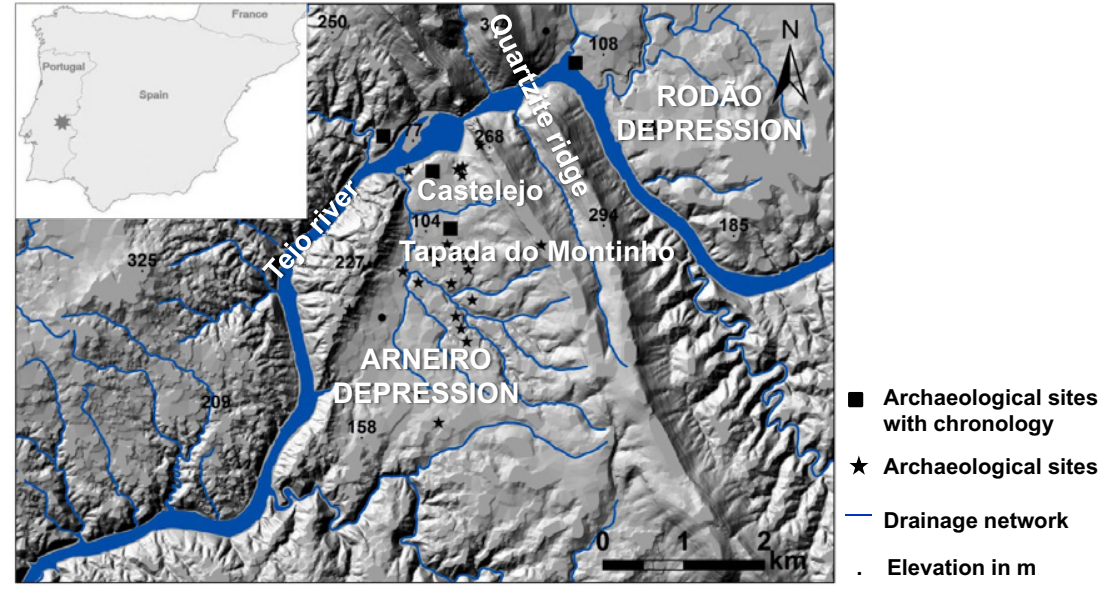

pogenic events and artefacts is very important to our understanding of natural driving mechanisms and cultural use of the landscape. In contrast to cosmogenic dating, which determines the length of time a clast has been at or close to the Earth's surface, trapped electron dating (including luminescence) can be used to determine the time since a clast was last exposed to daylight (i.e. the burial time).

In this study, we attempt to determine the age of the cobble pavement identified at Tapada do Montinho by applying OSL dating directly to the quartzite cobble surfaces. The dose measurements are carried out on slices of solid rock and multi-grain aliquots (63$300 \mu \mathrm{m}$ ) both separated from the $\sim 1.5-\mathrm{mm}$ outer surface of the cobbles. Routine tests associated with the single-aliquot regenerative-dose (SAR) protocol, including recycling ratio, recuperation, and dose recovery, are examined for both slices and grains. The penetration of light with depth is investigated for two cobbles to provide insights into the resetting of the OSL signal in these rock surfaces. The bleaching with depth model previously proposed by Sohbati et al. (2011) is developed further by taking the environmental dose rate into account, and the implications of this modification are considered. The constraining sediment layers above and below the cobble pavement, and the fine sediment from within the cobble layer itself, are also dated by quartz OSL and K-feldspar IRSL dating to provide support for the ages obtained from the cobbles.

\section{Site description and sampling}

The quartzite clasts in the cobble pavement in the Arneiro depression originate from low-grade metamorphism of Ordovician coastal sands and seem to have been transported during the Pleistocene from a quartzite ridge upstream or recycled from a previous terrace deposit. The cobbles are incorporated into an alluvial layer that contains middle Palaeolithic artefacts
(Cunha et al. in press). At the Castelejo site, this layer unconformably overlies the deposits of a terrace of the Tejo River, dated to $\sim 100 \mathrm{ka}$ at the top by K-feldspar IRSL (T4 terrace of the Lower Tejo River; Cunha et al. 2008) and underlies an aeolian unit with upper Paleolithic artefacts whose base has been dated to $\sim 30 \mathrm{ka}$ by quartz OSL (Cunha et al. in press).

Unfortunately, the location at Castelejo where the bounding sediment layers were dated was no longer available for re-excavation. However, we were able to sample what appeared to be a similar cobble pavement $(\sim 10 \mathrm{~cm}$ thick) at the TPM site $\sim 1 \mathrm{~km}$ to the south, although the sedimentary succession was shallower than that in Castelejo. Six quartzite cobbles $\sim 10 \mathrm{~cm}$ in diameter and sediment sample 108801 from the matrix of the cobble layer TPM II were sampled in the dark for OSL dating. The over- and underlying sediment layers were also sampled by hammering metal tubes into the sediment: sample 108803 from the top layer TPM I and sample 108803 from the bottom layer TPM III (Fig. 2).

\section{Sample preparation and analytical facilities}

Under subdued red-orange light, cores $\sim 10 \mathrm{~mm}$ diameter and up to $15 \mathrm{~mm}$ long were extracted from the surfaces of the cobbles using water-cooled diamond coring drills; these cores were then cut into $1-1.5 \mathrm{~mm}$ thick slices using a water-cooled diamond wafer blade $0.3 \mathrm{~mm}$ thick. The surface slices were treated by $40 \%$ $\mathrm{HF}$ for $40 \mathrm{~min}$ and $10 \% \mathrm{HCl}$ for $20 \mathrm{~min}$ to remove any weathering products. Some surface slices were crushed to recover grains; to minimize the possible effects of crushing, the slices were first washed in HF (40\%) for $30 \mathrm{~min}$ to weaken the bonds between the grains, and then gently disaggregated using an agate mortar. The partially disaggregated grains were sieved to 63-300 $\mu \mathrm{m}$, and those $>300 \mu \mathrm{m}$ replaced in HF for another $30 \mathrm{~min}$. The process was repeated several times, and finally the grains were treated with HF for 


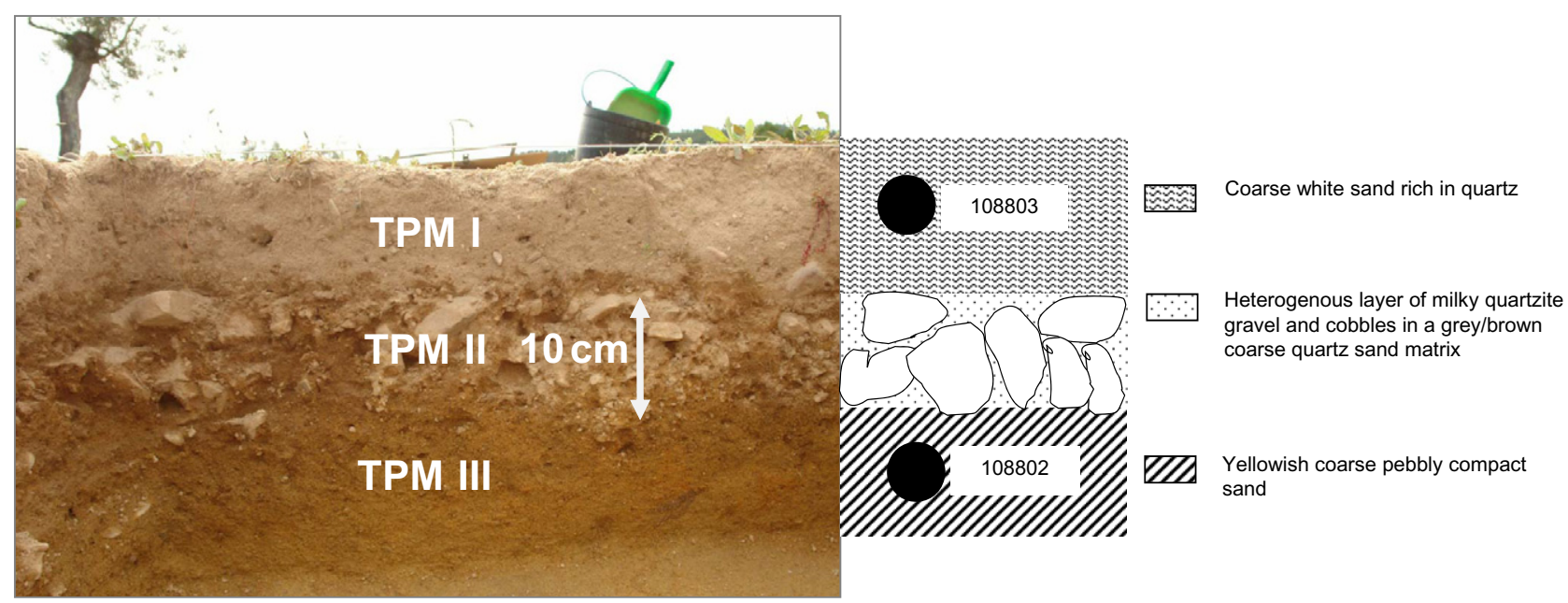

Fig. 2. Schematic view of the section sampled at the Tapada do Montinho archaeological site. This figure is available in colour at http://www.boreas.dk.

an additional 30 min to make sure that all the grains were treated for a total time of $>1 \mathrm{~h}$. The HF treatment was followed by $40 \mathrm{~min}$ in $10 \% \mathrm{HCl}$ to remove any precipitated fluorides.

The sediment samples were processed using conventional methods. Wet-sieving was used to isolate the grain size range $180-250 \mu \mathrm{m}$. This fraction was then treated with $10 \% \mathrm{HCl}$ to remove carbonates, followed by $10 \% \mathrm{H}_{2} \mathrm{O}_{2}$ to remove any reactive organic material. $\mathrm{K}$-rich feldspar grains were separated by floating in heavy liquid $\left(\rho=2.58 \mathrm{~g} \mathrm{~cm}^{-3}\right)$. These were then etched using $10 \% \mathrm{HF}$ for $40 \mathrm{~min}$ to dissolve the alphairradiated surface layer, and to remove surface weathering and coatings. Any fluoride contamination was removed using a $10 \% \mathrm{HCl}$ solution for $20 \mathrm{~min}$. A similar treatment was applied to extract quartz grains (using the fraction $>2.62 \mathrm{~g} \mathrm{~cm}^{-3}$ ), but with concentrated $\mathrm{HF}(40 \%)$ for $60 \mathrm{~min}$, followed by $10 \% \mathrm{HCl}$ for $40 \mathrm{~min}$ in the final stage.

All luminescence measurements were performed using a Risø TL/OSL reader (model TL-DA 20) (Bøtter-Jensen et al. 2010). A blue-light $(\lambda=470 \mathrm{~nm}$, $\sim 80 \mathrm{~mW} \mathrm{~cm}{ }^{-2}$ ) stimulated signal from intact slices and quartz grains was detected through a $\sim 7-\mathrm{mm}$ Hoya U-340 glass filter, and infrared $(\lambda=875 \mathrm{~nm}$, $\sim 135 \mathrm{~mW} \mathrm{~cm}^{-2}$ ) stimulated signal from K-rich feldspar grains was detected through a Schott BG39/Corning 7-59 filter combination (2 and $4 \mathrm{~mm}$, respectively). Beta irradiations used a ${ }^{90} \mathrm{Sr} /{ }^{90} \mathrm{Y}$ source mounted on the reader and calibrated for both disks and cups using $180-250 \mu \mathrm{m}$ calibration quartz grains. To calibrate the source for slices, six slices were sensitized and stabilized using successive cycles of dosing ( $90 \mathrm{~Gy})$ and heating to $450^{\circ} \mathrm{C}$. They were then given an accurately known dose of 5 Gy using a ${ }^{137} \mathrm{Cs}$ gamma source in a scatterfree geometry and measured using a SAR protocol. Slices were directly placed on the disk positions in the carousel. Quartz grains were mounted as large $(8 \mathrm{~mm})$ and K-rich feldspar grains as small $(2 \mathrm{~mm})$ aliquots in a monolayer using silicone oil on stainless steel disks (quartz) and cups (feldspar). The heating rate was $5{ }^{\circ} \mathrm{C}$ $\mathrm{s}^{-1}$ throughout. All thermal treatments and stimulations at temperatures higher than $200^{\circ} \mathrm{C}$ were carried out in nitrogen atmosphere. A pause of $100 \mathrm{~s}$ was inserted before the stimulation of slices to allow the entire slice volume to reach the measurement temperature. This pause was $10 \mathrm{~s}$ for steel disks and cups.

\section{Dosimetry}

The radionuclide concentrations $\left({ }^{238} \mathrm{U},{ }^{232} \mathrm{Th}\right.$ and $\left.{ }^{40} \mathrm{~K}\right)$ within the cobbles and in the surrounding sediment layers were measured using high-resolution gamma spectrometry. Rock samples and dried $\left(\right.$ at $\left.50^{\circ} \mathrm{C}\right)$ sediment samples were first ground and homogenized. The sediment samples were heated to $450^{\circ} \mathrm{C}$ for $24 \mathrm{~h}$ to remove any organic material. The material was then cast in wax to prevent radon loss and to provide a well-defined and reproducible counting geometry. Samples were then stored for at least three weeks to allow ${ }^{222} \mathrm{Rn}$ to reach equilibrium with its parent ${ }^{226} \mathrm{Ra}$ before being measured on a high-purity Germanium detector for $\sim 24 \mathrm{~h}$. Details of the gamma spectrometry calibration are given in Murray et al. (1987).

The long-term water contents of sediment samples were estimated based on the measured field and saturation water contents. The saturated water content of the cobbles is negligible.

For sediments, the internal beta dose rate to $\mathrm{K}$-feldspar grains from ${ }^{40} \mathrm{~K}$ was calculated based on an assumed effective potassium content of $12.5 \pm 0.5 \%$ (Huntley \& Baril 1997), and the beta contribution from ${ }^{87} \mathrm{Rb}$ was calculated assuming a ${ }^{87} \mathrm{Rb}$ content of 
Table 1. Summary of radionuclide concentrations (dry material), calculated dose rates, and estimated water-content values. Asterisk - see section 'Dosimetry' for details on the calculation of the total dose rate.

\begin{tabular}{|c|c|c|c|c|c|c|c|c|c|c|}
\hline $\begin{array}{l}\text { Sample } \\
\text { no. }\end{array}$ & $\begin{array}{l}\text { Sample } \\
\text { type }\end{array}$ & Layer & $\begin{array}{l}\text { Water } \\
\text { content } \\
(\%) \pm \mathrm{se}\end{array}$ & $\begin{array}{l}{ }^{238} \mathrm{U} \\
\left(\mathrm{Bq} \mathrm{kg}^{-1}\right) \pm \mathrm{se}\end{array}$ & $\begin{array}{l}{ }^{226} \mathrm{Ra} \\
\left(\mathrm{Bq} \mathrm{kg}^{-1}\right) \pm \mathrm{se}\end{array}$ & $\begin{array}{l}{ }^{232} \mathrm{Th} \\
\left(\mathrm{Bq} \mathrm{kg}^{-1}\right) \pm \mathrm{se}\end{array}$ & $\begin{array}{l}{ }^{40} \mathrm{~K} \\
\left(\mathrm{~Bq} \mathrm{~kg}^{-1}\right) \pm \mathrm{se}\end{array}$ & $\begin{array}{l}\text { Beta dose } \\
\text { rate }\left(\mathrm{Gy} \mathrm{ka}^{-1}\right) \pm \mathrm{se}\end{array}$ & $\begin{array}{l}\text { Gamma dose } \\
\text { rate }\left(\mathrm{Gy} \mathrm{ka}^{-1}\right) \pm \mathrm{se}\end{array}$ & $\begin{array}{l}\text { Total } \\
\text { dose rate* } \\
\left(\mathrm{Gy} \mathrm{ka}^{-1}\right) \pm \mathrm{se}\end{array}$ \\
\hline 109901-03 & Cobble & TPM II & 0 & $-0.02 \pm 4.8$ & $1.2 \pm 0.3$ & $1.1 \pm 0.3$ & $5 \pm 4$ & $0.02 \pm 0.02$ & $0.02 \pm 0.00$ & $1.33 \pm 0.13$ \\
\hline 109901-04 & Cobble & TPM II & 0 & $16.0 \pm 9.5$ & $-0.4 \pm 0.9$ & $0.2 \pm 0.9$ & $5 \pm 10$ & $0.08 \pm 0.05$ & $0.01 \pm 0.01$ & $1.35 \pm 0.13$ \\
\hline 109901-05 & Cobble & TPM II & 0 & $20.1 \pm 8.0$ & $2.6 \pm 0.6$ & $3.3 \pm 0.4$ & $20 \pm 7$ & $0.17 \pm 0.04$ & $0.08 \pm 0.01$ & $1.39 \pm 0.14$ \\
\hline 109901-06 & Cobble & TPM II & 0 & $22.5 \pm 12.1$ & $12.5 \pm 1.1$ & $27.1 \pm 1.3$ & $88 \pm 14$ & $0.55 \pm 0.06$ & $0.50 \pm 0.02$ & $1.59 \pm 0.16$ \\
\hline 109901-07 & Cobble & TPM II & 0 & $19.2 \pm 8.5$ & $10.2 \pm 0.8$ & $12.8 \pm 0.9$ & $71 \pm 9$ & $0.39 \pm 0.04$ & $0.29 \pm 0.01$ & $1.70 \pm 0.17$ \\
\hline 108801 & Sediment & TPM II & $6 \pm 4$ & $30.4 \pm 7.1$ & $24.1 \pm 0.6$ & $32.6 \pm 0.7$ & $542 \pm 12$ & $1.79 \pm 0.04$ & $1.01 \pm 0.02$ & $2.80 \pm 0.12$ \\
\hline 108802 & Sediment & TPM III & $7 \pm 4$ & $99.6 \pm 7.6$ & $81.5 \pm 1$ & $33 \pm 1$ & $753 \pm 14$ & $2.89 \pm 0.06$ & $1.60 \pm 0.07$ & $5.20 \pm 0.21$ \\
\hline 108803 & Sediment & TPM I & $7 \pm 4$ & $37.5 \pm 6.6$ & $25.2 \pm 0.6$ & $36.4 \pm 0.7$ & $606 \pm 13$ & $2.01 \pm 0.04$ & $1.11 \pm 0.03$ & $3.07 \pm 0.05$ \\
\hline
\end{tabular}

$400 \pm 100$ ppm (Huntley \& Hancock 2001). A small internal alpha contribution of $0.10 \pm 0.05 \mathrm{~Gy} \mathrm{ka}^{-1}$ from internal ${ }^{238} \mathrm{U}$ and ${ }^{232} \mathrm{Th}$ was also included in the dose rates, derived from ${ }^{238} \mathrm{U}$ and ${ }^{232} \mathrm{Th}$ concentration measurements made by Mejdahl (1987). For quartz, an internal dose rate of $0.010 \pm 0.002 \mathrm{~Gy} \mathrm{ka}^{-1}$ was assumed (Vandenberghe et al. 2008). The radionuclide concentrations were converted to dose-rate data using the conversion factors from Olley et al. (1996). All radionuclide concentrations and dry, infinite-matrix beta and gamma dose rates are summarized in Table 1.

To estimate the total dose rate to the surface of the cobbles we use

$$
\dot{D}_{\text {total }}=\dot{D}_{\beta, \text { total }}+\dot{D}_{\gamma, \text { total }}+\dot{D}_{\text {cosmic }},
$$

where $\dot{D}_{\beta, \text { total }}$ is the beta dose rate due to the adjacent sediment layers + the beta dose rate from the cobble itself, and $\dot{D}_{\gamma, \text { total }}$ is the gamma dose rate due to the adjacent sediment layers + the gamma dose rate from the cobble itself.

As the detailed relationship of each cobble surface with the adjacent sediment layer was not known, three extreme geometries were considered, by assuming that the rock surface was in contact with sediment at the top, at the bottom or from within the cobble layer itself, in order to calculate the external dose rates (both gamma and beta). The cobble layer TPM II was assumed to be a 4:1 mixture of cobble and intercalated sediment. The dry, infinite-matrix beta and gamma dose rates of sediments reported in Table 1 were first adjusted for the effects of the estimated water contents for each layer (Aitken 1985). An average of the three limiting conditions above was then taken as the net external dose rate.

To calculate the total beta dose rate $\dot{D}_{\beta, \text { total }}$, an external beta dose rate of $2.1 \pm 0.3 \mathrm{~Gy} \mathrm{ka}^{-1}$ was first estimated by averaging over layers TPM I, II and III to an adjacent cobble surface (based on the data of Table 1). This dose rate was then averaged over the surface 1.5-mm layer of a cobble by modifying equation (H.13) from Aitken (1985: appendix H) for a single-sided sample, to give an average external beta dose rate of
$0.42 \pm 0.06 \mathrm{~Gy} \mathrm{ka}^{-1}$ to the surface layer. The contribution from the internal beta dose rate arising from the cobble itself (including the self-beta dose rate from the sample layer) was calculated individually for each cobble using the same equation (H.13 from Aitken 1985) and dry, infinite-matrix beta dose rates of the cobbles. The thickness of the sample layer was $1.5 \mathrm{~mm}$.

For the total gamma dose rate $\dot{D}_{\gamma, \text { total }}$, the gamma dose-rate contributions from the over- and underlying layers and from the cobble layer were calculated using the principle of superposition (Aitken 1985: appendix $\mathrm{H})$. Values of $0.78,0.69$ and $0.91 \mathrm{~Gy} \mathrm{ka}^{-1}$ were estimated assuming that the cobble surface lay adjacent to layer TPM I, II or III, respectively, giving an average external infinite-matrix gamma dose rate of $0.79 \pm 0.06 \mathrm{~Gy} \mathrm{ka}^{-1}$. The net surface gamma dose rate (i.e. the sum of external and internal dose rates) was then derived using equations (H.4) and (H.5) from Aitken (1985) and the observation by Mejdahl (1983) that the average gamma dose rate in a spherical rock of density $2.6 \mathrm{~g} \mathrm{~cm}^{-3}$ is $2.6 \mathrm{~d} \%$ of the infinite-matrix dose rate, where $d$ is the diameter of the sphere in centimetres.

The contribution from cosmic radiation to the dose rate was calculated following Prescott \& Hutton (1994) assuming an uncertainty of $5 \%$.

\section{Luminescence characteristics of quartzite cobbles}

A single-aliquot regenerative-dose (SAR) protocol (Murray \& Wintle 2000, 2003) was used for both cobble slices and multi-grain aliquots (see Table 2). For slices, thermal pretreatments of 260 and $220^{\circ} \mathrm{C}$ were applied for $100 \mathrm{~s}$ before the regenerative and test doses respectively. To minimize the effect of potential feldspar contamination, an infrared stimulation at $125^{\circ} \mathrm{C}$ was carried out for $100 \mathrm{~s}$ before a pulsed blue stimulation for $200 \mathrm{~s}$ (post-IR POSL) at the same temperature (Thomsen et al. 2008). A high-temperature blue-light stimulation at $280^{\circ} \mathrm{C}$ for $100 \mathrm{~s}$ was also applied at the end of each cycle to reduce recuperation (Murray \& 
Table 2. Outline of the SAR OSL and post-IR POSL protocols (Murray \& Wintle 2000, 2003; Thomsen et al. 2008).

\begin{tabular}{|c|c|c|c|c|}
\hline \multirow[t]{2}{*}{ Step } & \multicolumn{2}{|l|}{ Slices } & \multicolumn{2}{|l|}{ Grains } \\
\hline & Treatment & Observed & Treatment & Observed \\
\hline 1 & Dose & & Dose & \\
\hline 2 & Preheat $\left(260^{\circ} \mathrm{C}\right.$ for $\left.100 \mathrm{~s}\right)$ & & Preheat $\left(260^{\circ} \mathrm{C}\right.$ for $\left.10 \mathrm{~s}\right)$ & \\
\hline 3 & Infrared stimulation $\left(125^{\circ} \mathrm{C}\right.$ for $\left.100 \mathrm{~s}\right)$ & & - & \\
\hline 4 & Pulsed blue stimulation $\left(125^{\circ} \mathrm{C}\right.$ for $\left.200 \mathrm{~s}\right)$ & $\mathrm{L}_{\mathrm{x}}$ & Blue stimulation $\left(125^{\circ} \mathrm{C}\right.$ for $\left.40 \mathrm{~s}\right)$ & $\mathrm{L}_{\mathrm{x}}$ \\
\hline 5 & Test dose & & Test dose & \\
\hline 6 & Preheat $\left(220^{\circ} \mathrm{C}\right.$ for $\left.100 \mathrm{~s}\right)$ & & Cut heat $\left(220^{\circ} \mathrm{C}\right)$ & \\
\hline 7 & Infrared stimulation $\left(125^{\circ} \mathrm{C}\right.$ for $\left.100 \mathrm{~s}\right)$ & & - & \\
\hline 8 & Pulsed blue stimulation $\left(125^{\circ} \mathrm{C}\right.$ for $\left.200 \mathrm{~s}\right)$ & $\mathrm{T}_{\mathrm{x}}$ & Blue stimulation $\left(125^{\circ} \mathrm{C}\right.$ for $\left.40 \mathrm{~s}\right)$ & $T_{x}$ \\
\hline 9 & Blue stimulation $\left(280^{\circ} \mathrm{C}\right.$ for $\left.100 \mathrm{~s}\right)$ & & Blue stimulation $\left(280^{\circ} \mathrm{C}\right.$ for $\left.40 \mathrm{~s}\right)$ & \\
\hline 10 & Return to 1 & & Return to 1 & \\
\hline
\end{tabular}

Wintle 2003). The multi-grain aliquots were measured in a similar manner to the slices but with shorter thermal pretreatments: the $260^{\circ} \mathrm{C}$ preheat after the regenerative dose was for $10 \mathrm{~s}$ and there was a cut-heat (with immediate cooling) at $220^{\circ} \mathrm{C}$ after the test dose. All stimulations were performed in continuous wave (CW) for $40 \mathrm{~s}$, and no infrared stimulation was used (Table 2). For calculations, the initial $0.8 \mathrm{~s}$ of the signal less an early background of $1.6 \mathrm{~s}$ was used. The earlybackground subtraction was chosen to minimize the possible effect of the more difficult to bleach and more thermally unstable medium and slow components (Jain et al. 2003; Singarayer \& Bailey 2004); these effects may give rise to both age over- and underestimations (Li \& Li 2006; Pawley et al. 2010). No IRSL signal was detected from the slices. The sensitivity of quartz was variable from sample to sample, but in all cases, for both slices and grains, it was dominated by the fast component. Figure 3 shows a comparison between the decay curves from a slice and a multi-grain aliquot from sample 109901-05, and an aliquot of Risø calibra- tion quartz. The post-IR pulsed OSL curve was measured using an on-time of $50 \mu \mathrm{s}$ and an off-time of $200 \mu$ s. To allow a direct comparison of the pulsed and CW data, every five channels of the pulsed data set have been summed, to give an equivalent $\mathrm{CW}$ curve (Fig. 3).

The dose-response curve of a slice taken from a depth of $\sim 4 \mathrm{~mm}$ from sample 109901-07 is shown in Fig. 4. Recycling ratios and recuperation were measured for both slices and grains from all samples. The average recycling ratios for slices and grains were $1.01 \pm 0.01 \quad(n=9)$ and $0.98 \pm 0.02(n=36)$, respectively, and the average recuperations were $0.23 \pm 0.12 \%(n=9)$ and $-0.22 \pm 0.17 \%(n=36)$ of the natural signal (Fig. 5). A dose-recovery test was performed for grains extracted from sample 109901-04. Three aliquots were bleached for $100 \mathrm{~s}$ twice using blue LEDs, with a pause of $\sim 3 \mathrm{~h}$ between exposures to allow for any charge trapped in shallow refuge traps (especially that associated with the $110^{\circ} \mathrm{C} \mathrm{TL}$ peak) to return to the OSL trap; they were then given a dose close to the equivalent

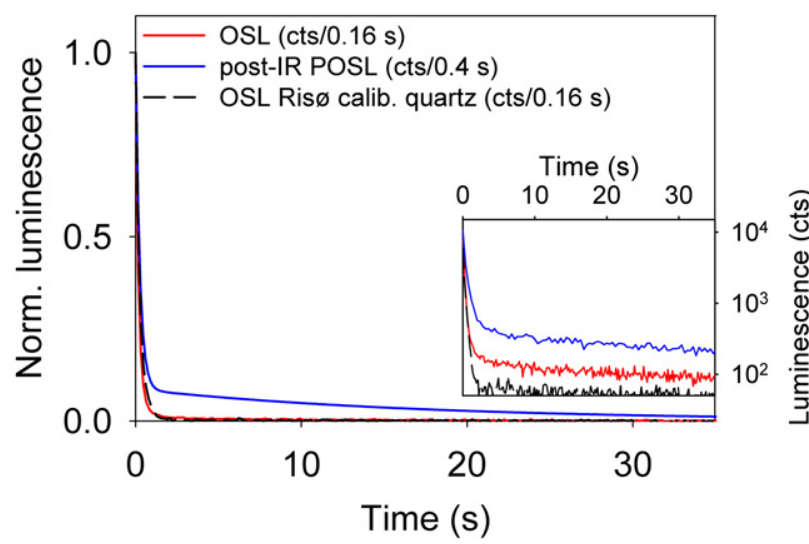

Fig. 3. Normalized decay curves from a solid slice (blue) and a multigrain aliquot (red) from sample 109901-05 are compared with the normalized decay curve of Risø calibration quartz (dashed line). To allow a direct comparison of the pulsed (blue) and CW data, every five channels of the pulsed data set have been summed, to give an equivalent $\mathrm{CW}$ curve. The inset shows the signals on a logarithmic scale. This figure is available in colour at http://www.boreas.dk.

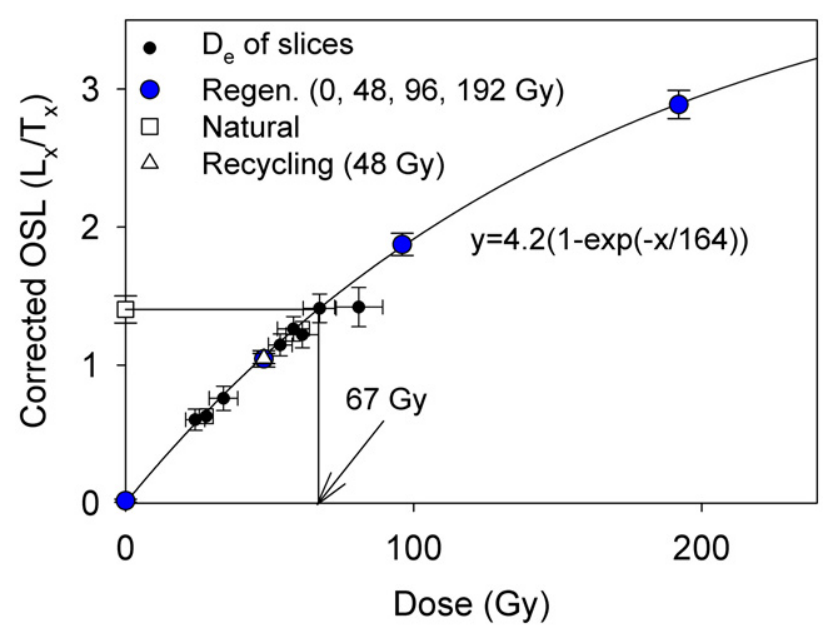

Fig. 4. The dose-response curve of an inner slice from the depth of $\sim 4 \mathrm{~mm}$ from cobble 109901-07. The $\mathrm{D}_{\mathrm{e}}$ values from other slices at different depths are also shown as black circles. This figure is available in colour at http://www.boreas.dk. 
Fig. 5. Distribution of recycling ratios and recuperation signal as a percentage of natural signal for $(\mathrm{A}, \mathrm{C})$ slices and $(\mathrm{B}, \mathrm{D})$ large aliquots of quartz grains from all samples.

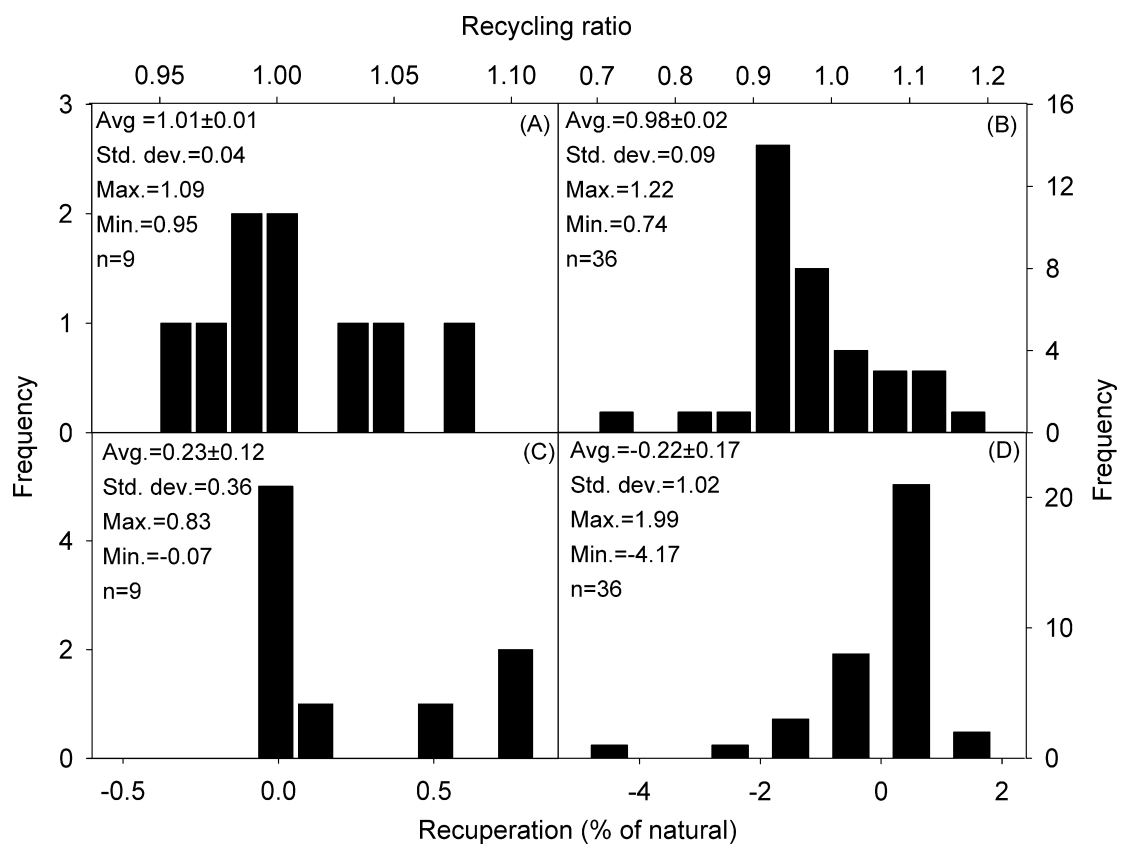

dose $\left(D_{e}\right)$. The average measured-to-given dose ratio for the preheat temperature of $260^{\circ} \mathrm{C}$ was $0.98 \pm 0.03$ $(n=3)$, showing that a known laboratory dose can be recovered within acceptable limits using this preheat temperature. A dose-recovery test was also undertaken using rock slices. Three inner slices, from each of four cobbles, were bleached in a similar manner to the grains but with a stimulation time of $1000 \mathrm{~s}$. They were then given a dose of $\sim 25 \mathrm{~Gy}$ and measured using the SAR protocol (Table 2). The average measured-to-given dose ratio was $1.06 \pm 0.02(n=12)$, showing that a known laboratory dose can be adequately recovered using our protocol.

\section{Variation of dose with depth}

One of the assumptions in luminescence dating is that the samples were sufficiently exposed to sunlight during transportation, so that any dose in the sample is set to zero prior to deposition. Several authors have shown that the longer the exposure time, the further into the rock is the luminescence signal reset (Polikreti et al. 2002, 2003; Laskaris \& Liritzis 2011). One can expect that the residual luminescence signal might be fully reset at the surface, and then increase towards saturation at a depth sufficiently far into the rock that the charge de-trapping effects of light are negligible compared with the rate of charge trapping from the dose rate. To find out if the surfaces of the cobbles in this study had been well exposed to light before burial, the gradient of the natural OSL signal with depth was investigated by measuring the variation of the OSL signal with depth for cobbles 109901-04 and 109901-07.
Figure 6 shows the resulting corrected natural OSL signal $\left(\mathrm{L}_{\mathrm{n}} / \mathrm{T}_{\mathrm{n}}\right)$ from each slice plotted against depth. Interestingly, there appears to be a decrease in luminescence from the surface to a depth of $\sim 2 \mathrm{~mm}$ in both samples. This could be due to the low internal radioactivity of the cobbles (see Table 1) and attenuation of the external beta dose rate; if so, such an effect could only be observed if the rock had been bleached to at least this depth $(\sim 2 \mathrm{~mm})$. A light penetration of $\sim 2 \mathrm{~mm}$ would be in agreement with what has been reported as the depth of complete bleaching in granitic rocks after several minutes of exposure to sunlight (Habermann et al. 2000; Sohbati et al. 2011).

In order to investigate the information contained in these luminescence profiles, and in particular to test

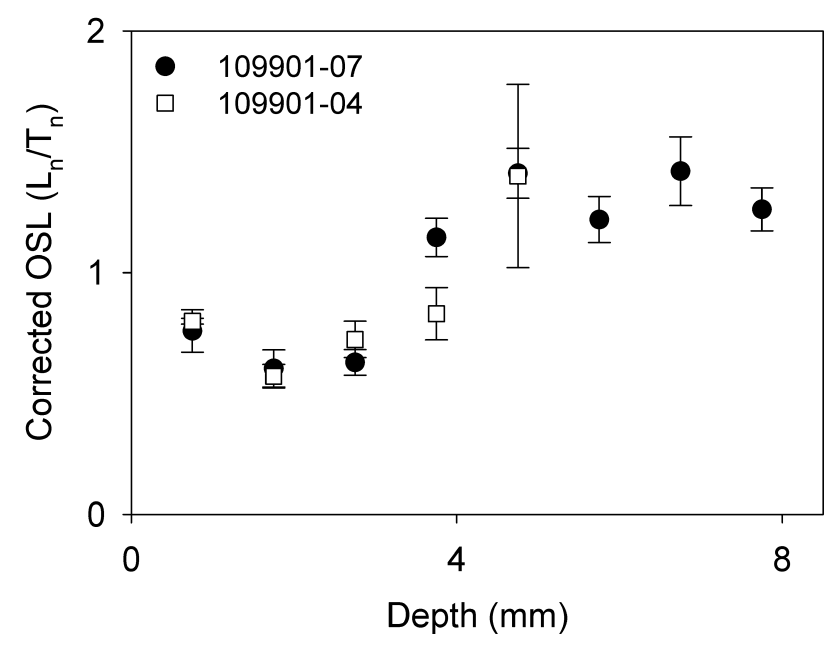

Fig. 6. Variation of luminescence with depth for the two cobbles 109901-04 and 109901-07 based on slices. 


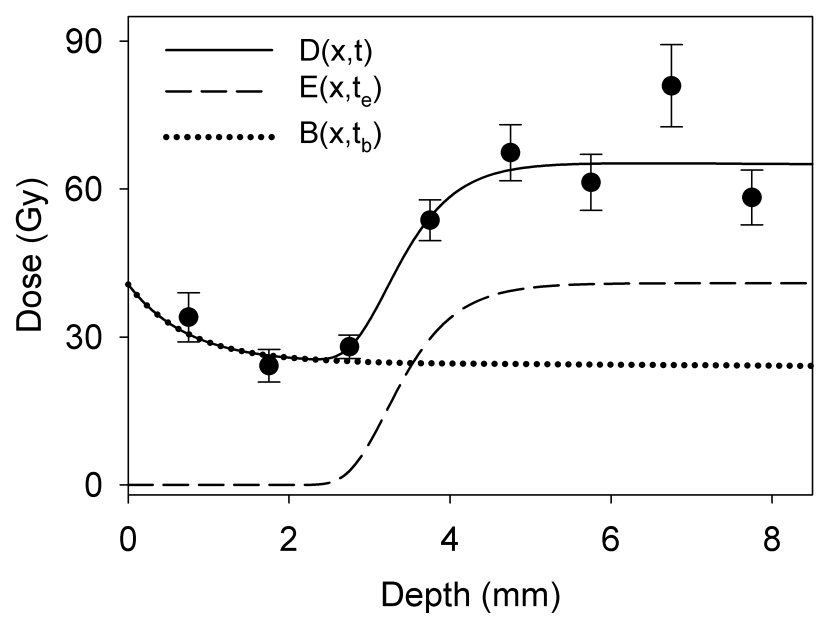

Fig. 7. Variation of dose with depth for cobble 109901-07 based on slices as in Fig 6. The solid line represents the model fitted to the data points. The dashed line shows the variation of dose with depth at the time of deposition predicted by the model, and the dotted line shows the accumulation of dose inside the cobble during burial.

whether the drop in the luminescence level in the first $2 \mathrm{~mm}$ from the surface could be due to the attenuation of the external beta dose rate, the data from sample 109901-07 were re-expressed in terms of dose (the $D_{e}$ of each slice was estimated using SAR). For comparison, these $D_{e}$ values are all plotted (black circles) on the dose-response curve of the slice from $\sim 4 \mathrm{~mm}$ depth (Fig. 4); it can be seen that all estimates of $\mathrm{D}_{\mathrm{e}}$ are consistent with this growth curve. In this dose range ( $<70$ Gy) the relationship between $L_{x} / T_{x}$ and $D_{e}$ is approximately linear $\left(\mathrm{D}_{0} \sim 150 \mathrm{~Gy}\right.$; Fig. 4$)$; as a result the trend in $D_{e}$ values with depth is very similar to that of luminescence $\left(\mathrm{L}_{n} / \mathrm{T}_{\mathrm{n}}\right)$. The $\mathrm{D}_{\mathrm{e}}$ in the two surface slices, to a depth of $\sim 2 \mathrm{~mm}$, is $\sim 30 \mathrm{~Gy}$; this then increases smoothly to a constant dose of $\sim 66 \mathrm{~Gy}$ at a depth of $\sim 5 \mathrm{~mm}$ (Fig. 7). In principle, these data include information on both exposure (prior to burial) and possible different burial periods in the history of the cobble. Assuming that the rate of charge trapping due to natural radiation is negligible in comparison to the rate of de-trapping at the time of sunlight bleaching, the duration of light exposure $t_{\mathrm{e}}$ and the duration of exposure to ionising radiation $t_{\mathrm{b}}$ can be considered to be independent. Thus, the dependence of dose on depth $x$ and time $t$ can be described as

$D(x, t)=E\left(x, t_{e}\right)+B\left(x, t_{b}\right)$,

where the functions $E\left(x, t_{e}\right)$ and $B\left(x, t_{b}\right)$ account for the exposure and burial periods, respectively.

Sohbati et al. (2011) have shown that the bleaching of luminescence with depth $x$ and exposure time $t_{\mathrm{e}}$ can be described by a double exponential function. If luminescence is linearly dependent on dose (see above and Fig. 4), a similar function (i.e. double exponential) can be used to explain the resetting of dose with depth and exposure time. Thus, here we are also able to represent the light exposure term $E\left(x, t_{e}\right)$ in the form of a double exponential function. Assuming that external beta and gamma dose rates decay exponentially with penetration into the rock, and internal dose rates build up exponentially, the burial term $B\left(x, t_{b}\right)$ can be formulated by using the principle of superposition. Accordingly, the overall dependence of dose with depth $x$ and time $t$ can be approximated by

$$
\begin{aligned}
D(x, t)= & D_{0} e^{-P e^{-\mu x}}+0.5 \dot{D}_{\beta e} t_{b} e^{-a x}+\dot{D}_{\beta i} t_{b}\left\{1-0.5 e^{-b x}\right\} \\
& +0.8 \dot{D}_{\gamma e} t_{b} e^{-c x}+\dot{D}_{\gamma i} t_{b}\left\{1-0.8 e^{-c x}\right\}+C t_{b} .
\end{aligned}
$$

Here $D_{0}$ is the dose that would have been measured in the cobble before daylight bleaching (assumed independent of depth), $P$ is the product of photoionization cross-section, photon flux and exposure time $t_{e}$, and $\mu$ is the light attenuation coefficient (see Sohbati et al. 2011). $\dot{D}_{\beta e}$ is the average of the water-content-corrected infinite-matrix beta dose rates of the surrounding sediment layers. $\dot{D}_{\beta i}$ is the infinite-matrix internal beta dose rate of the cobble. $a$ and $b$ are external and internal beta-dose-rate attenuation coefficients, respectively. $\dot{D}_{\gamma e}$ is the average of gamma-dose-rate contributions from the over- and underlying layers and from the cobble layer. $\dot{D}_{\gamma i}$ is the infinite-matrix internal gamma dose rate. The factor of 0.8 was calculated by expressing the external gamma dose rate at the cobble surface (see above) as a fraction of the average infinite-matrix external gamma dose rate. $c$ is the gamma-dose-rate attenuation factor, and $C$ is the cosmic dose rate. The external beta and gamma dose rates are the same as calculated above, and the infinite-matrix internal dose rates are given in Table 1. The linear attenuation coefficients of external $(a)$ and internal $(b)$ beta dose rates of 1.4 and $1.7 \mathrm{~mm}^{-1}$, respectively, were calculated using a weighted average of the attenuation factors for uranium and thorium series reported by Aitken (1985: appendix $\mathrm{H}$ ) modified for rock (density of $2.6 \mathrm{~g} \mathrm{~cm}^{-3}$ ), and an attenuation factor of $1.50 \mathrm{~mm}^{-1}$ was assumed for potassium. The gamma-dose-rate attenuation factor $c$ of $0.01 \mathrm{~mm}^{-1}$ was calculated using the variation in the weighted average of the fractional doses of uranium, thorium and potassium with depth, taken from Aitken (1985: appendix H).

The solid line in Fig. 7 shows the best fit of Equation (3) to our dose observations. The model represents the data very well, and reproduces the small drop in dose at the surface of the cobble, confirming that this arises because of attenuation of the external beta dose rate. The fitted parameter values are summarized in Table 3.

It is remarkable that the $\sim 67$ Gy dose measured from the inner slices (depth $>5 \mathrm{~mm}$ ) is not in saturation (see Fig. 4). This implies that at some time in the past the cobble was exposed to daylight for a long enough period for sufficient light to reach the middle of the 
Table 3. The fitted parameters for cobble 109901-07 using the data shown in Fig. 7. The parameters were obtained by fitting in SigmaPlot 11 .

\begin{tabular}{lcl}
\hline Parameter & Value & Units \\
\hline $\mathrm{D}_{\mathrm{o}}$ & 41 & $\mathrm{~Gy}$ \\
$P$ & 880 & - \\
$\mu$ & 2 & $\mathrm{~mm}^{-1}$ \\
$t_{\mathrm{b}}$ & 19 & $\mathrm{ka}$ \\
$D_{\beta \mathrm{e}}$ & 2 & $\mathrm{~Gy} \mathrm{ka}^{-1}$ \\
$a$ & 1.4 & $\mathrm{~mm}^{-1}$ \\
$D_{\beta \mathrm{i}}$ & 0.4 & $\mathrm{~Gy} \mathrm{ka}^{-1}$ \\
$b$ & 1.7 & $\mathrm{~mm}^{-1}$ \\
$D_{\gamma \mathrm{e}}$ & 0.8 & $\mathrm{~Gy} \mathrm{ka}^{-1}$ \\
$D_{\gamma \mathrm{i}}$ & 0.3 & $\mathrm{~Gy} \mathrm{ka}^{-1}$ \\
$c$ & 0.01 & $\mathrm{~mm}^{-1}$ \\
$C$ & 0.3 & $\mathrm{~Gy} \mathrm{ka}^{-1}$ \\
\hline
\end{tabular}

cobble to reset the luminescence signal throughout the volume of the clast (resetting by a heating event cannot be completely dismissed, although there is no evidence for fire damage on the surface of the clast). This resetting event must have occurred some significant time before the most recent (presumably much shorter) light exposure of the cobble, during which exposure was sufficient to fully reset only the outer $\sim 2 \mathrm{~mm}$ of the clast. We can be confident that the outer 1-mm layer was fully bleached because the burial dose in the second millimetre is less than that at the surface. This can only have arisen if both layers were fully bleached; incomplete bleaching would have led to a rapid rise in dose with depth. Modelling fully supports this conclusion (Fig. 7).

\section{$\mathrm{D}_{\mathrm{e}}$ measurements and age calculation}

Following the testing of the applicability of the SAR protocol and confirmation of the likelihood of complete bleaching of the cobbles' surfaces before burial, the measurements of $D_{e}$ were obtained using both surface slices and grains. Three slices and nine multigrain aliquots were measured from each of four

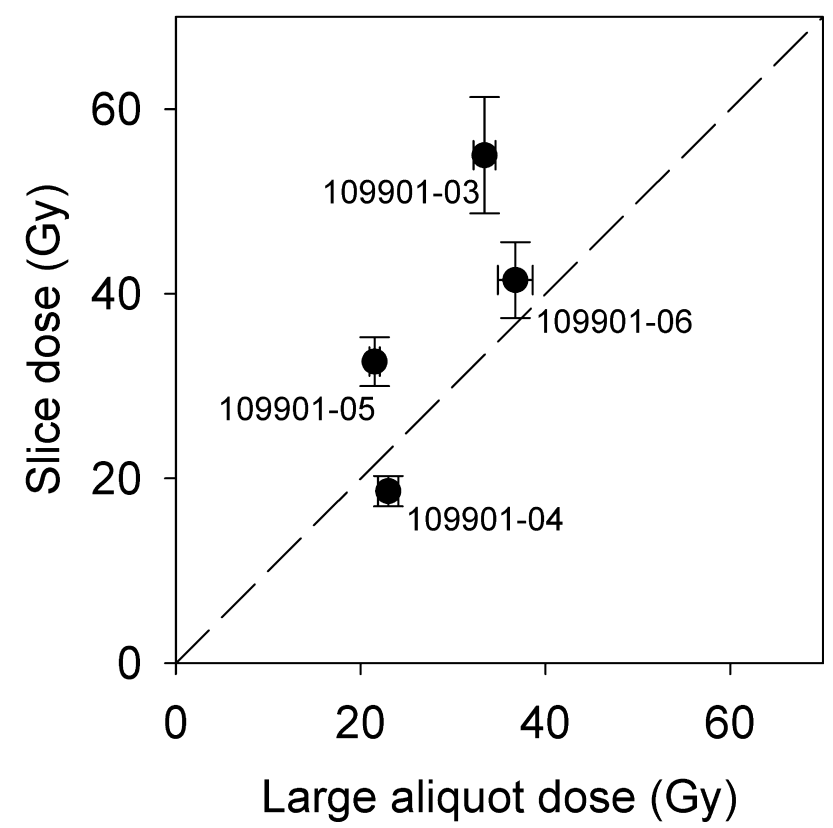

Fig. 8. Comparison between doses from slices and large aliquots of quartz grains.

cobbles. The results are summarized in Table 4. The doses obtained from intact slices for samples 109901-04 and 109901-06 are indistinguishable from those from large aliquots of quartz grains extracted from the same cobbles. However, the slice doses for samples 109901-03 and 109901-05 are 20 and 10 Gy larger than their associated grain doses, respectively (Fig. 8). Two ages were calculated for each cobble, based on the mean dose values from slices and large aliquots from the upper $1 \mathrm{~mm}$ of the surface (Table 4 ). Rock slices resulted in an age range of 41 to $14 \mathrm{ka}$, while multigrain aliquots gave an age range of 25 to $16 \mathrm{ka}$ (Table 4).

\section{Testing the age control}

The unexpectedly young ages obtained from most of the cobbles at TPM cast doubt on the integrity of the

Table 4. Summary of the $\mathrm{D}_{\mathrm{e}}$ values and calculated ages for slices and grains from the outer $1 \mathrm{~mm}$ of the cobbles and grains constraining the sediment layers. Asterisk - this fading-corrected age was determined using the conventional K-feldspar IRSL signal at $50^{\circ} \mathrm{C}$.

\begin{tabular}{|c|c|c|c|c|c|c|c|c|}
\hline \multirow[t]{2}{*}{ Sample no. } & \multirow[t]{2}{*}{ Sample type } & \multirow[t]{2}{*}{ Layer } & \multicolumn{3}{|l|}{ Slices } & \multicolumn{3}{|c|}{ Large aliquots } \\
\hline & & & $\mathrm{D}_{\mathrm{e}}(\mathrm{Gy}) \pm \mathrm{se}$ & $n$ & Age $(\mathrm{ka}) \pm \mathrm{se}$ & $\mathrm{D}_{\mathrm{e}}(\mathrm{Gy}) \pm \mathrm{se}$ & $n$ & Age $(\mathrm{ka}) \pm \mathrm{se}$ \\
\hline 109901-03 & Cobble & TPM II & $55 \pm 6$ & 3 & $41.3 \pm 6.3$ & $33.4 \pm 1.2$ & 9 & $25.1 \pm 2.7$ \\
\hline 109901-04 & Cobble & TPM II & $18.6 \pm 1.6$ & 3 & $14 \pm 2$ & $23.0 \pm 1.1$ & 9 & $17 \pm 2$ \\
\hline 109901-05 & Cobble & TPM II & $33 \pm 3$ & 3 & $23 \pm 3$ & $21.5 \pm 0.6$ & 9 & $15.5 \pm 1.6$ \\
\hline 109901-06 & Cobble & TPM II & $41 \pm 4$ & 3 & $26 \pm 4$ & $37 \pm 2$ & 9 & $23.2 \pm 2.6$ \\
\hline 109901-07 & Cobble & TPM II & $34 \pm 5$ & 1 & $20.1 \pm 3.5$ & - & - & - \\
\hline 108801 & Sediment & TPM II & - & - & - & $11.2 \pm 1.4$ & 6 & $4.0 \pm 0.5$ \\
\hline 108802 & Sediment & TPM III & - & - & - & $204 \pm 16$ & 9 & $51 \pm 5^{*}$ \\
\hline 108803 & Sediment & TPM I & - & - & - & $1.33 \pm 0.24$ & 21 & $0.43 \pm 0.08$ \\
\hline
\end{tabular}


cobble layer at this location; we expected them to be older than the presumed overlying sediment layer at Castelejo ( $\sim 30 \mathrm{ka})$ and comparable with the middle Palaeolithic artefacts (50 to $40 \mathrm{ka}$ ) incorporated in the cobble pavement at TPM (Cunha et al. 2008, in press). To investigate this inconsistency, sediment samples from the underlying (108802, TPM III) and overlying (108803, TPM I) horizons, and from the matrix of the cobble pavement (108801, TPM II) were dated to provide age control.

As quartz OSL was found to be in saturation in sample 108802 from the underlying layer TPM III, this sample was measured using the conventional IRSL signal at $50^{\circ} \mathrm{C}$ as used by Cunha et al. (2008). The recycling ratio, recuperation, and dose-recovery tests show that the SAR protocol is applicable to this signal. The average recycling ratio is $1.010 \pm 0.003(n=9)$ and the average recuperation is $3.3 \pm 0.2 \%(n=9)$ of the natural signal. For the dose-recovery test three aliquots were bleached for $\sim 4 \mathrm{~h}$ in a Hönle SOL2 solar simulator, at a lamp-sample distance of $\sim 80 \mathrm{~cm}$ to avoid heating the samples. They were then given a laboratory dose close to the equivalent dose. Three additional aliquots were also measured to determine the amount of the residual dose remaining after bleaching in the laboratory. After subtraction of the residual dose of $2.9 \pm 0.6 \mathrm{~Gy}$, the ratio of the measured dose to the given dose is $0.89 \pm 0.01(n=3)$, showing that a known laboratory dose can be recovered within $\sim 10 \%$. The anomalous fading rate was quantified by measuring the ' $\mathrm{g}$ 'value (Aitken 1985) following the method of Auclair et al. (2003). Three aliquots were measured using SAR cycles with a regenerative dose of $\sim 170 \mathrm{~Gy}$ and a test dose of $\sim 56 \mathrm{~Gy}$. The ratios of the regenerated signals $\left(\mathrm{L}_{\mathrm{x}}\right)$ to the test-dose signals $\left(\mathrm{T}_{\mathrm{x}}\right)$ were measured repeatedly, with time delays of $\sim 0.18 \mathrm{~h}$ for prompt measurements and $12 \mathrm{~h}$ for delay measurements. The ' $\mathrm{g}$ '-values were calculated using equation (4) of Huntley \& Lamothe (2001) and normalized to a measurement delay time $\left(\mathrm{t}_{\mathrm{c}}\right)$ of 2 days after irradiation. The average $\mathrm{g}_{2 \text { day }}$ value is $2.7 \pm 0.3 \% /$ decade $(n=3)$. This is comparable to the $\mathrm{g}_{2 \mathrm{day}}$ values of $\sim 3 \%$ /decade reported by Cunha et al. (2008) for their samples from the same region. Correcting the apparent age for fading using this ' $\mathrm{g}$ 'value (Huntley \& Lamothe 2001), sample 108802 gives an age of $51 \pm 5 \mathrm{ka}$ (Table 4); Buylaert et al. (2011) have reported accurate fading-corrected ages for known-age (Eemian) sediment samples from Denmark with $D_{e}$ values of at least up to $\sim 200 \mathrm{~Gy}$ similar to the $D_{e}$ of sample 108802. It is thus unlikely that this layer is older than $60 \mathrm{ka}$.

Samples 108801 from the sandy matrix of the cobble pavement TPM II and 108803 from the overlying layer TPM I were dated using the routine quartz OSL. Recycling ratio, recuperation and dose-recovery tests prove the applicability of the SAR protocol for both samples. The dose-recovery ratios were $1.02 \pm 0.07$ $(n=3)$ and $0.94 \pm 0.02(n=3)$ for samples 108801 and 108803, respectively. Sample 108801 gave an age of $4.0 \pm 0.5 \mathrm{ka}$, and the overlying sample 108803 an age of $0.43 \pm 0.08 \mathrm{ka}$ (Table 4).

\section{Discussion}

It is remarkable how much information on multiple resetting and burial events is available from the dosedepth profile of cobble 109901-07 (and probably 109901-04). The fact that the dose ( 66 Gy) recorded today by the inner part of cobble 109901-07 is not in saturation and does not vary significantly with depth implies that the whole cobble was once exposed to light for long enough to be entirely bleached (or, less likely, heated sufficiently to be completely reset). The model presented above can be used to deduce the shape of the dose-depth variation curve at the time of deposition, using the fitted values of $D_{0}, P$ and $\mu$ (dashed line in Fig. 8). This fitting suggests that the inner part of the cobble was unbleached at the time of last deposition, and had recorded a dose of $41 \mathrm{~Gy}$ (the residual dose at deposition) and subsequently acquired an additional dose to give the present-day value of $66 \mathrm{~Gy}$. The present-day dose rates are $\dot{D}_{\beta i} \cong 0.4, \dot{D}_{\gamma i} \cong 0.3$ and $\dot{D}_{\gamma e} \cong 0.8 \mathrm{~Gy} \mathrm{ka}^{-1}$ (see Table 1); if we assume that the external gamma dose rate has not changed significantly during the history of the cobble, this first (complete) resetting event must have taken place at $\sim 45 \mathrm{ka}$, consistent with the age of the underlying terrace of $51 \pm 5 \mathrm{ka}$.

The timing of the second, more superficial, resetting and subsequent burial event can be derived in two ways. From the fitting discussed above, the burial age is $\sim 19 \mathrm{ka}$ (Table 3). From direct measurement of the surface slices from this cobble, this last burial occurred $20 \pm 4 \mathrm{ka}$. Several of the cobble surfaces record a bleaching event at about this time (see Table 4).

At least in principle, we can also derive information about the length of time the cobble surface was exposed to daylight before the second burial event. The parameter $P$ in Equation (3) is the product of the photoionization cross-section $\sigma\left(\mathrm{cm}^{2}\right)$, the photon flux $\varphi$ $\left(\mathrm{cm}^{-2} \mathrm{~s}^{-1}\right)$, and the exposure time $t_{\mathrm{e}}(\mathrm{s})$ (Sohbati et al. 2011). Thus the exposure time $t_{\mathrm{e}}$ can be estimated from the value of $P$ derived from fitting, if we know the product of $\sigma \times \varphi$. Sohbati et al. (2011) give $\sigma$ data for feldspar taken from exposed granite cobbles from a modern beach in Denmark and $\varphi$ data derived from the literature. Although these data are based on feldspar, a comparison with the quartz data of Jain et al. (2003) and Spooner (1994) suggests that differences between quartz and feldspar photoionization cross-sections are small compared with the uncertainties arising from our lack of knowledge of the light spectrum as it penetrates the rock. Using the data from Sohbati et al. (2011) we 
estimate average values of $\sim 7 \times 10^{-3}$ and $\sim 5 \times 10^{-5}\left(\mathrm{~s}^{-1}\right)$ for $\sigma \times \varphi$ for the wavelength ranges of $300 \mathrm{~nm}-10 \mu \mathrm{m}$ and $700 \mathrm{~nm}-10 \mu \mathrm{m}$, respectively. Thus, taking the effective wavelength range of $300 \mathrm{~nm}-10 \mu \mathrm{m}$, cobble 109901-07 appears to have been exposed for $\sim 2$ days; using the longer effective wavelength range of $700 \mathrm{~nm}-$ $10 \mu \mathrm{m}$ predicts an exposure time of $\sim 200$ days. Sohbati et al. (2011) remarked that the exposure times they calculated were much shorter than those expected for their samples. They suggested that this underestimation could be attributed to the slow (non-exponential) bleaching rate of feldspar luminescence; this qualification is not relevant here, because the data are derived from the quartz OSL signal. However, a more accurate estimation of the exposure time requires a better understanding of the dependence of photon flux and photoionization cross-section on wavelength and depth (see discussion in Sohbati et al. 2011).

In samples 109901-03 and 109901-05 the natural doses from slices are significantly larger than those from grains, whereas in samples 109901-04 and 109901-06 these two dose measurements are similar. Given the differences in dose rates from cobbles, the sediment matrix and the surrounding sediment layers (Table 1), this disagreement may reflect the different surfaces from which the slices and grains were sampled. No record was made at the time of sampling of the exact relationship of cobble surfaces to sediment; in retrospect this was a mistake. On the other hand, Sohbati et al. (2011) also found systematic dose differences using the infrared signals from grains and whole rock slices taken from the same surfaces in some modern samples; they were unable to explain these differences. It may be that a similar phenomenon is present here.

The age of $51 \pm 5 \mathrm{ka}$ for the sediment sample 108802 (TPM3) is much younger than the reported age of $\sim 100 \mathrm{ka}$ for the underlying layer of the cobble pavement at Castelejo (both ages estimated using the same methodology; Cunha et al. 2008), implying that this layer was probably deposited during a more recent alluvial event than that which emplaced the top of the T4 terrace at Castelejo. Most of the cobble ages are significantly younger than the expected age of $>30 \mathrm{ka}$ based on the quartz OSL age obtained from the overlying sediment layer at Castelejo and on the evidence of middle Palaeolithic industries found in situ in the cobble pavement at Castelejo (Cunha et al. in press). Nevertheless, ages based on rock slices suggest that one cobble surface (109901-03), and one inner part of a cobble (109901-07) and possibly another (109901-04) experienced a resetting event about 50 to $40 \mathrm{ka}$, consistent with the age of the underlying terrace of $51 \pm 5 \mathrm{ka}$, and with the expected age range of 100 to $30 \mathrm{ka}$. The surfaces of the other four cobbles all record light-exposure events in the range 26 to $14 \mathrm{ka}$, suggesting that some (but not all) of the cobbles were exposed to daylight perhaps more than once in this period, presumably by erosion of the sediment overlying the cobble pavement. The multi-grain ages support this picture - all four surface ages lie in the range 26 to $16 \mathrm{ka}$. The difference in age between slices and grains for cobble 109901-03 may arise because these samples were taken from different surfaces, as discussed above.

The age of $4.0 \pm 0.5 \mathrm{ka}$ for sediment sample 108801 from within the cobble layer TPM II is also much younger than the cobble age range of 41 to $14 \mathrm{ka}$. This disagreement between the cobbles and their surrounding sediment and between the cobbles themselves reinforces our suspicions concerning the integrity of the cobble layer; the inter-cobble sandy sediment could easily have been washed out and replaced during a reworking event without affecting most of the cobble surfaces. This idea of recent erosion and exposure is made more likely by the observation that sample 108803 from the overlying sediment layer TPM I gives an age of only $0.43 \pm 0.08 \mathrm{ka}$; clearly it is probable that at least the top of the cobble layer was very close to the surface within the last few hundred years before final burial, perhaps as a result of agricultural activity.

\section{Conclusions}

The possibility of dating a naturally deposited cobble pavement in the Mousterian archaeological site of Tapada do Montinho has been investigated by applying OSL dating directly to the cobble surfaces. The routine tests of recuperation, recycling ratio and dose recovery show that the SAR protocol is applicable to both quartz grains and intact slices recovered from the surface of the cobbles in this study and that they can be used for OSL dating.

Some aspects of this investigation were compromised by apparent reworking of the cobble pavement and the sediment matrix within the pavement. Nevertheless, we were able to identify a resetting event recorded by the surface of one cobble and the inner volume of two other cobbles that occurred at about 50 to $40 \mathrm{ka}$, consistent with the IRSL age of the underlying sediment platform and with the age control based on earlier work. We conclude that the OSL dating of rock surfaces seems to be a viable method for dating various geological and archaeological phenomena, including some that cannot be dated using sediments. Unlike individual sediment grains, rock surfaces can be exposed for prolonged periods, and we have shown here for the first time that (i) such long exposure periods can leave a distinct bleaching record in the luminescence/dose profile with depth into a cobble, and (ii) it may be possible to identify and date multiple deposition events in one sample. In our study we were able to identify the presence of two such bleaching events and date the two subsequent burial events, one at $\sim 45 \mathrm{ka}$, and a more recent event at 
$\sim 20 \mathrm{ka}$. We were also able to deduce that the earlier of these bleaching events was much more complete (the OSL signal $>5 \mathrm{~mm}$ into the rock seems to have been fully bleached) than the later, and that this later light exposure may have taken place on a time scale of days to months.

It is both very surprising and exciting to be able to recover such a wealth of information from one sample clast. Finer-grained sediments do not retain such information, or at least not in such an unambiguous form, and it may well prove that coarser clasts are actually to be preferred over sandy sediments when the completeness of bleaching is in doubt.

Acknowledgement. - The authors would like to thank Prof. Ann Wintle, Dr. Kiriaki Polikreti and Prof. Jan A. Piotrowski for the careful review of this manuscript and their constructive comments. Dr. António A. Martins is thanked for kindly providing Fig. 1.

\section{References}

Aitken, M. J. 1985: Thermoluminescence Dating. 359 pp. Academic Press, London.

Auclair, M., Lamothe, M. \& Huot, S. 2003: Measurement of anomalous fading for feldspar IRSL using SAR. Radiation Measurements 37, 487-492.

Bøtter-Jensen, L., Thomsen, K. J. \& Jain, M. 2010: Review of optically stimulated luminescence (OSL) instrumental developments for retrospective dosimetry. Radiation Measurements 45, 253-257.

Buylaert, J. P., Huot, S., Murray, A. S. \& Van den haute, P. 2011: Infrared stimulated luminescence dating of an Eemian (MIS 5e) site in Denmark using K-feldspar. Boreas 40, 46-56.

Cunha, P. P., Almeida, N. A. C., Aubry, T., Martins, A. A., Murray, A. S., Buylaert, J.-P., Sohbati, R., Raposo, L. \& Rocha, L. In press: Pleistocene sedimentary and human occupation records in the Arneiro depression (Lower Tejo River, central eastern Portugal). Geomorphology.

Cunha, P. P., Martins, A. A., Huot, S., Murray, A. \& Raposo, L. 2008: Dating the Tejo river lower terraces in the Ródão area (Portugal) to assess the role of tectonics and uplift. Geomorphology 102, $43-54$.

Habermann, J., Schilles, T., Kalchgruber, R. \& Wagner, G. A. 2000: Steps towards surface dating using luminescence. Radiation Measurements 32, 847-851.

Huntley, D. J. \& Baril, M. R. 1997: The K content of the K-feldspars being measured in optical dating or in thermoluminescence dating. Ancient TL 15, 11-13.

Huntley, D. J. \& Hancock, R. G. V. 2001: The Rb contents of the $\mathrm{K}$-feldspar grains being measured in optical dating. Ancient TL 19, 43-46.

Huntley, D. J. \& Lamothe, M. 2001: Ubiquity of anomalous fading in K-feldspars and the measurement and correction for it in optical dating. Canadian Journal of Earth Sciences 38, 1093-1106.

Jain, M., Murray, A. S. \& Bøtter-Jensen, L. 2003: Characterisation of blue-light stimulated luminescence components in different quartz samples: implications for dose measurement. Radiation Measurements 37, 441-449.

Laskaris, N. \& Liritzis, I. 2011: A new mathematical approximation of sunlight attenuation in rocks for surface luminescence dating. Journal of Luminescence 131, 1874-1884.

Li, B. \& Li, S.-H. 2006: Comparison of $\mathrm{D}_{\mathrm{e}}$ estimates using the fast component and the medium component of quartz OSL. Radiation Measurements 41, 125-136.

Liritzis, I. 2011: Surface dating by luminescence: an overview. Geochronometria 38, 292-302.

Mejdahl, V. 1983: Feldspar inclusion dating of ceramics and burnt stones. PACT 9, 351-354.

Mejdahl, V. 1987: Internal radioactivity in quartz and feldspar grains. Ancient TL 5, 10-17.

Murray, A. S., Marten, R., Johnston, A. \& Martin, P. 1987: Analysis for naturally occurring radionuclides at environmental concentrations by gamma spectrometry. Journal of Radioanalytical and Nuclear Chemistry 115, 263-288.

Murray, A. S. \& Wintle, A. G. 2000: Luminescence dating of quartz using an improved single-aliquot regenerative-dose protocol. Radiation Measurements 32, 57-73.

Murray, A. S. \& Wintle, A. G. 2003: The single aliquot regenerativedose protocol: potential for improvements in reliability. Radiation Measurements 37, 377-381.

Olley, J., Murray, A. S. \& Roberts, R. G. 1996: The effects of disequilibria in the uranium and thorium decay chains on the burial dose rates in fluvial sediments. Quaternary Science Reviews 15, 751-760.

Pawley, S. M., Toms, P., Armitage, S. J. \& Rose, J. 2010: Quartz luminescence dating of Anglian Stage (MIS 12) fluvial sediments: Comparison of SAR age estimates to the terrace chronology of the Middle Thames valley, UK. Quaternary Geochronology 5, 569582.

Polikreti, K., Michael, C. T. \& Maniatis, Y. 2002: Authenticating marble sculpture with thermoluminescence. Ancient TL 20, 11-18.

Polikreti, K., Michael, C. T. \& Maniatis, Y. 2003: Thermoluminescence characteristics of marble and dating of freshly excavated marble objects. Radiation Measurements 37, 87-94.

Prescott, J. R. \& Hutton, J. T. 1994: Cosmic ray contributions to dose rates for luminescence and ESR dating: large depths and long-term variations. Radiation Measurements 23, 497-500.

Simms, A. R., DeWitt, R., Kouremenos, P. \& Drewry, A.-M. 2011: A new approach to reconstructing sea levels in Antarctica using optically stimulated luminescence of cobble surfaces. Quaternary Geochronology 6, 50-60.

Singarayer, J. S. \& Bailey, R. M. 2004: Component-resolved bleaching spectra of quartz optically stimulated luminescence: preliminary results and implications for dating. Radiation Measurements $38,111-118$

Sohbati, R., Murray, A. S., Jain, M., Buylaert, J.-P. \& Thomsen, K. J. 2011: Investigating the resetting of OSL signals in rock surfaces. Geochronometria 38, 249-258.

Spooner, N. A. 1994: On the optical dating signal from quartz. Radiation Measurements 23, 593-600.

Thomsen, K. J., Jain, M., Murray, A. S., Denby, P. M., Roy, N. \& Bøtter-Jensen, L. 2008: Minimizing feldspar OSL contamination in quartz UV-OSL using pulsed blue stimulation. Radiation Measurements 43, 752-757.

Vandenberghe, D., De Corte, F., Buylaert, J.-P., Kučerac, J. \& Van den haute, P. 2008: On the internal radioactivity in quartz. Radiation Measurements 43, 771-775. 